Bertha Chávez • Juan Pablo Méndez

Alfredo Ulloa-Aguirre • Fernando Larrea • Felipe Vilchis

\title{
Eight novel mutations of the androgen receptor gene in patients with androgen insensitivity syndrome
}

Received: May 7, 2001 / Accepted: June 28, 2001

\begin{abstract}
Androgen insensitivity syndrome (AIS) is an $\mathrm{X}$-linked genetic disorder of male sexual differentiation caused by mutations in the androgen receptor $(A R)$ gene. A reliable genotype-phenotype correlation in these patients does not exist as yet. Here we report the molecular studies performed on eight individuals with AIS. Exon-specific polymerase chain reaction (PCR), single-strand conformation polymorphism, and sequencing analyses, were performed in exons 2 to 8 of the $A R$ gene. In one case, total cellular RNA was extracted from genital skin fibroblasts and reverse transcriptase-PCR was performed. Six different point mutations leading to amino acid substitutions (P682T, Q711E, G743E, F827V, H874R, D879Y), one splicejunction mutation ( $\mathrm{g} \rightarrow \mathrm{c}$ at +5 , exon 6/intron 6), and a missense mutation without amino acid substitution (S888S) were identified. All mutations, including a de novo mutation, were previously undescribed on the steroid binding domain. Of the eight mutations identified, four led to a complete female phenotype (codons 743, 827, 874 and the donor splice site +5 ), two were detected in phenotypic females with partial virilization (codons 682 and 711), and two were present in phenotypic male subjects with undervirilized external genitalia, thus indicating that all of these sites determine AR functional activity.
\end{abstract}

Key words Steroid receptors - Male pseudohermaphroditism - Splice-junction mutation - Silent mutation - Ambiguous genitalia

B. Chávez · A. Ulloa-Aguirre $\cdot$ F. Larrea $\cdot$ F. Vilchis $(\bowtie)$

Department of Reproductive Biology, Instituto Nacional de Ciencias Médicas y Nutrición Salvador Zubirán, Vasco de Quiroga \#15,

Tlalpan, CP 14000, México D.F., México

Tel. +1-525-573-1200 ext. 2423; Fax +1-525-655-9859

e-mail: vilchisuf@prodigy.net.mx

J.P. Méndez

Medical Research Unit in Developmental Biology, Hospital de

Pediatría, IMSS, México City, Mexico

\section{Introduction}

Androgen insensitivity syndrome (AIS) is an X-linked hereditary disorder that leads to male pseudohermaphroditism with variable phenotypes. This defective response results from the impairment of androgen receptor (AR) function in activating androgen responsive genes in target cells (McPhaul et al. 1993). The phenotype in 46,XY affected individuals varies depending on the extent of the AR defect, ranging from subjects with complete androgen insensitivity syndrome (CAIS) where a female phenotype is observed, to patients with genital ambiguity who present with partial androgen insensitivity syndrome (PAIS). Patients with CAIS exhibit female external genitalia with a short vagina, usually sparse or absent pubic hair, normalsized testes located in the abdominal or inguinal area with hypoplastic Wolffian derivatives; Müllerian ducts are generally absent. Patients with PAIS have a spectrum of virilization defects ranging from clitoromegaly and posterior fusion of labia majora to hypospadias with gynecomastia (French et al. 1990; Quigley et al. 1995).

The AR belongs to the nuclear receptor superfamily and has four functional domains encoded by eight exons (Lubahn et al. 1989). The N-terminal domain encoded by exon 1 is involved in transcriptional activation of target genes by androgens. The central section encoded by exons 2 and 3 comprises two "zinc-finger"-like structures; this domain is responsible for binding to androgen response elements in the promoter region of target genes. A hinge region, located between the DNA-binding domain and the steroid binding domain (SBD), is encoded by the 5 'region of exon 4, and contains the major part of the AR nuclear targeting signal. The $\mathrm{C}$-terminal domain, encoded by exons 4 ( 3 'region) to 8 , is involved in high-affinity ligand binding (Simental et al. 1991). The cloning of cDNA for human AR (Lubahn et al. 1988; Chang et al. 1988) has allowed detection of numerous molecular lesions, most of them being missense mutations spread throughout the coding region, although some "hot spots" have been identified (Quigley et al. 1995). In this study, we identified mutations in the $A R$ 
gene of a group of patients with AIS and found eight new single-base mutations, all of them located within the SBD.

\section{Subjects and methods}

\section{Patients}

Molecular studies were performed on eight 46,XY individuals who were previously diagnosed with AIS. Patient 1 presented at 9 months of age with bilateral inguinal herniae, clitoromegaly, and slight labial fusion. Patient 2 presented at 11 years of age, having bilateral inguinal herniae, pseudovagina, and clitoromegaly. Patients 3 and 6, with CAIS phenotypes, were previously described (UlloaAguirre et al. 1986, 1990). Patient 4 (CAIS) presented at 16 years old with primary amenorrhea, absence of sexual hair, a short vagina, and hypoplasia of labia majora and minora; breast development was Tanner 4. Patient 5 presented at 18 years of age with a female phenotype, absence of axillary hair, and scarce pubic hair. She was diagnosed with CAIS. Patient 7 was born with a penoscrotal hypospadias and cryptorchidism. At puberty, he developed bilateral gynecomastia and exhibited a female-like distribution of body fat. His facial and axillary hair was scarce. Patient 8 was admitted to the hospital at 3 years of age, presenting with perineal hypospadias and left cryptorchidism. The study was approved by the Medical Ethics Committee of the Instituto Nacional de Ciencias Médicas y Nutrición Salvador Zubirán and informed consent was obtained from each of the patients or their parents.

\section{Methods}

DNA isolation was performed from ethylenediamine tetraacetate (EDTA) blood samples or genital skin fibroblasts of the patients and controls by standard methods (John et al. 1991). DNA fragments from exons $2-8$ of the $A R$ gene were amplified by the polymerase chain reaction (PCR) using primers previously reported (DeBellis et al. 1992). Reactions were carried out in a final volume of $25 \mu \mathrm{l}$ containing $0.5-0.8 \mu \mathrm{g}$ genomic DNA, $2 \mu \mathrm{M}$ each deoxyribonucleotide triphosphate, $1.25 \mu \mathrm{M}$ of each oligonucleotide primer, $1.5 \mathrm{mM} \mathrm{MgCl}, 50 \mathrm{mM} \mathrm{KCl}, 10 \mathrm{mM}$ Tris $\mathrm{HCl}(\mathrm{pH} 8.3), 4 \%$ dimethylsulfoxide, and 2.0U of Thermostable DNA polymerase (Perkin Elmer, Branchburg, NJ, USA). Reactions were subjected to 25 cycles of amplification at $94^{\circ} \mathrm{C}$ for $1 \mathrm{~min}$, annealing at $58-62^{\circ} \mathrm{C}\left(58^{\circ} \mathrm{C}\right.$ for exons $2,3,4$ and 5; $60^{\circ} \mathrm{C}$ for exons 6 and $8 ; 62^{\circ} \mathrm{C}$ for exon 7) for $1 \mathrm{~min}$, and extension at $72^{\circ} \mathrm{C}$ for $1 \mathrm{~min}$.

Single-stranded conformational polymorphism (SSCP) analysis of PCR products was performed according to the method of Orita (1989), using $\left[\alpha-{ }^{32} \mathrm{P}\right]$ deoxycytidine triphosphate as described elsewhere (Vilchis et al. 2000). Sequencing of the mutant and normal PCR fragments was carried out with the Thermosequenase $\left(\left[\alpha-{ }^{33} \mathrm{P}\right]\right.$ dideoxynucleotide triphosphate) terminator cycle sequencing kit (Amersham,
Cleveland, OH, USA), following the manufacturer's recommendations. Genital skin fibroblasts were propagated in cell culture from normal foreskin (46,XY control subjects) or a biopsy specimen from patients as previously described (Medina et al. 1982; Ulloa-Aguirre et al. 1988). Androgenbinding activity in cultured fibroblasts was determined under conditions similar to those described previously (Ulloa-Aguirre et al. 1988, 1990). Briefly, normal or mutant cellular pellets were resuspended in a buffer Tris $\mathrm{HCl}$, $20 \mathrm{mmol} / 1$ [pH 7.4], containing; $1.5 \mathrm{mmol} / 1$ EDTA, $0.25 \mathrm{mmol} / 1$ dithiothreitol, $10 \%$ glycerol, $10 \mathrm{mmol} / 1$ sodium molybdate and then homogenized with a teflon pestle. The resulting homogenates were centrifuged at $105000 \mathrm{~g}$ for $1 \mathrm{~h}$ at $4^{\circ} \mathrm{C}$ to obtain the soluble fraction. Aliquots of cytosol $(100 \mu \mathrm{l})$ were incubated at $4^{\circ} \mathrm{C}$ with $2.0 \mathrm{nmol} / 1\left[{ }^{3} \mathrm{H}\right]-$ Dihydrotestosterone $\left(\left[1,2,4,5,6,7-{ }^{3} \mathrm{H}(\mathrm{N})\right] 5 \alpha\right.$-DHT; sp. act. $110 \mathrm{Ci} / \mathrm{mmol}$, New England Nuclear, Boston, MA, USA), with or without an excess (200-fold) of nonlabeled DHT to assess nonspecific binding. Bound and free steroid fractions were separated by dextran-coated charcoal method. Each determination was carried out in triplicate and repeated at least twice. Results were expressed as femtomoles of bound $\left[{ }^{3} \mathrm{H}\right]$-DHT per milligram of protein (mean values \pm S.D.).

Total cellular RNA was extracted from genital skin fibroblasts using Trizol reagent (Gibco-BRL, Grand Island, NY, USA). RNA was reverse-transcribed into cDNA with the SuperScript preamplification system (Life Technologies, Grand Island, NY, USA). Aliquots (100ng) of the cDNA from patient 4 and from a normal control were amplified by PCR using a set of primers designed from exon 6 (sense, 5'-ATGTACAGCCAGTGTGTCCGAATG) and exon 8 of the AR (antisense 5'-CTGGGTGTGGAAATA GATGGGCT). After amplification, PCR products were analyzed in a $1.0 \%$ agarose gel stained with ethidium bromide and visualized by UV fluorescence. Subsequently, both mutant and control DNA fragments were purified and sequenced as described earlier.

\section{Results}

No gross deletions of the $A R$ gene were detected by PCR in any of the patients studied. Abnormalities in migration were detected by SSCP in all individuals. Sequencing analysis demonstrated eight new single-base mutations including a de novo mutation (Table 1 ). Patient 1 presented a $\mathrm{C} \rightarrow \mathrm{A}$ transversion within exon 4 , changing codon 682 from proline to threonine (Fig. 1). Patient 2 had a $\mathrm{C} \rightarrow \mathrm{G}$ transversion at codon 711, also in exon 4 , which was responsible for a glutamine to glutamic acid substitution (Fig. 1). In patient 3, a $\mathrm{G} \rightarrow \mathrm{A}$ transition was detected at position 743 in exon 5 . This change was responsible for a glycine to glutamic acid substitution (Fig. 1).

Patient 4 had a mutation $(\mathrm{g} \rightarrow \mathrm{c})$ at position +5 of the (exon 6/intron 6) splice donor site, which was not found in his mother (Fig. 2); this intronic mutation appears to prevent the splicing of intron 6. Amplification of the AR from 
Table 1. Mutations in the $A R$ gene from patients with AIS

\begin{tabular}{llllllll}
\hline Patient & Form & Exon & Nucleotide $^{\mathrm{a}}$ & Base change & aa change & Binding $^{\mathrm{b}}$ & Mutation \\
\hline 1 & PAIS & 4 & 2406 & CCA $\rightarrow$ ACA & Pro $\rightarrow$ Thr & $\downarrow(14.3 \pm 1.9)$ & P682T \\
2 & PAIS & 4 & 2493 & CAG $\rightarrow$ GAG & Gln $\rightarrow$ Glu & $+(31.0 \pm 7.7)$ & Q711E \\
3 & CAIS & 5 & 2590 & GGG $\rightarrow$ GAG & Gly $\rightarrow$ Glu & $+(28.5 \pm 6.2)$ & G743E \\
4 & CAIS & & +5 & g $\rightarrow$ c & & $-(0.00)$ & +5 intron 6 \\
5 & CAIS & 7 & 2841 & TTT $\rightarrow$ GTT & Phe $\rightarrow$ Val & $+(25.2 \pm 5.9)$ & F827V \\
6 & CAIS & 8 & 2980 & CAT $\rightarrow$ CGT & His $\rightarrow$ Arg & $-(0.00)$ & H874R \\
7 & PAIS & 8 & 2997 & GAC $\rightarrow$ TAC & Asp $\rightarrow$ Tyr & $+(26.8 \pm 2.6)$ & D879Y \\
8 & PAIS & 8 & 3026 & AGC $\rightarrow$ AGT & Ser $\rightarrow$ Ser & $+(18.7 \pm 7.8)$ & S888S \\
\hline
\end{tabular}

CAIS, complete androgen insensitivity syndrome; PAIS, partial androgen insensitivity syndrome; aa, amino acid

${ }^{a}$ According to the numeration of Lubahn et al. 1989

${ }^{\mathrm{b}}$ AR binding: +, positive binding (15-55 fmol/mg protein); $\downarrow$, diminished binding (4-15 fmol/mg protein); - , negative binding $(<3.0 \mathrm{fmol} / \mathrm{mg}$ protein). AR binding in normal control individuals $(34.5 \pm 20.5 \mathrm{fmol} / \mathrm{mg}$ protein)

\section{Exon 4}
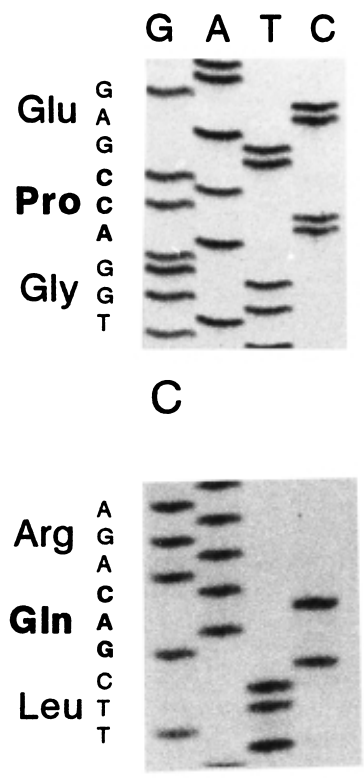

C

\section{Exon 5}

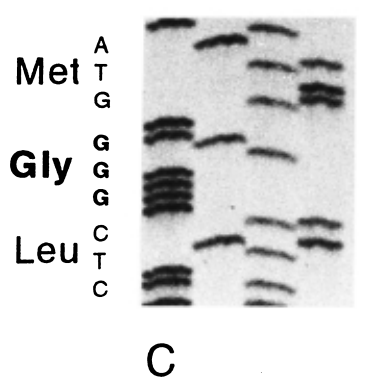
corresponds to the SBD. Patients 1 and 2 presented a mutation in exon 4 and a PAIS phenotype. Patient 1 had a $\mathrm{C} \rightarrow \mathrm{A}$ substitution at nucleotide 2406 that leads to a nonconservative mutation of residue 682 , which is highly conserved among the steroid receptor subgroup. It is thought that highly conserved residues are the most com-

Fig. 1. Partial sequence of exons 4 and 5 of the $A R$ gene. $\mathrm{A} \mathrm{C} \rightarrow \mathrm{A}$ mutation in patient 1 that converts proline to threonine at position 682 is observed in the upper panel. A $\mathrm{C} \rightarrow \mathrm{G}$ transversion in patient 2 causing Gln711-Glu is shown in the middle panel. $\mathrm{A} \mathrm{G} \rightarrow \mathrm{A}$ transition in patient 3 causing Gly743-Glu is depicted in the lower panel. Portions of sequencing gels with control DNAs $(C)$ are shown on the left

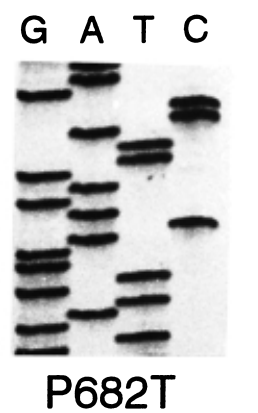

A Glu

G A Thr G Gly $T$

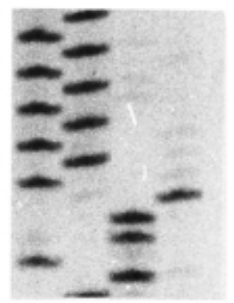

$\begin{array}{ll}\text { A } & \text { Arg } \\ \text { G } & \text { Arg } \\ \text { A } & \\ \text { G } & \\ \text { A } & \text { Glu } \\ \text { G } & \\ \text { C } & \\ \text { T } & \text { Leu } \\ \text { T } & \end{array}$

Q711E
Leu Discussion
Androgen insensitivity leads to incomplete virilization of individuals with a normal 46,XY karyotype. Molecular studies in patients with AIS are critical for generating a correlation between AR genotypes and clinical phenotypes, and these studies contribute to the elaboration of a structure-function map of the AR based on naturally occurring mutations. Thus far there are more than 200 different reported molecular lesions throughout the eight exons that constitute the gene. Diverse mutations of the AR have been described, not only in AIS, but also in prostate and breast cancers (French et al. 1990; López-Otín and Diamandis 1998; Ahmed et al. 2000; Sawai et al. 2000).

In our eight patients, a single-base mutation was always identified and all except one were within the region that

patient 4's cDNA (enclosing exons 6-8) by reverse transcriptase-PCR resulted in an amplimer of $1223 \mathrm{bp}$ (normal (about $800 \mathrm{bp}$ ) together with a coding segment of $423 \mathrm{bp}$ (Fig. 2). Sequencing analyses of this DNA fragment (data not shown) essentially conforms to the sequence of the 1989), thus indicating a defective splicing. Subject 5 prea $T \rightarrow G$ transversion in exon 7 that changes the sense sixth mutation was an $\mathrm{A} \rightarrow \mathrm{G}$ transition in exon 8 , changing $\mathrm{G} \rightarrow \mathrm{T}$ transversion in exon 8 resulted in a change from aspartic acid to tyrosine at amino acid 879 (Fig. 4). Finally, $\mathrm{C} \rightarrow \mathrm{T}$ missense mutation that leaves intact serine 888 (AGT instead of AGC) was the only alteration found in the AR of patient 8 (Fig. 4).

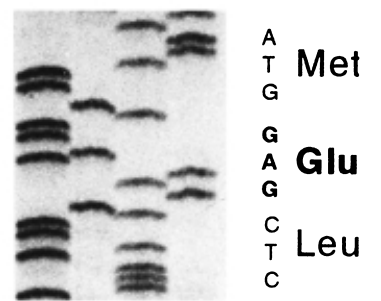

\section{G743E}




\section{Exon 6/Intron 6 junction}
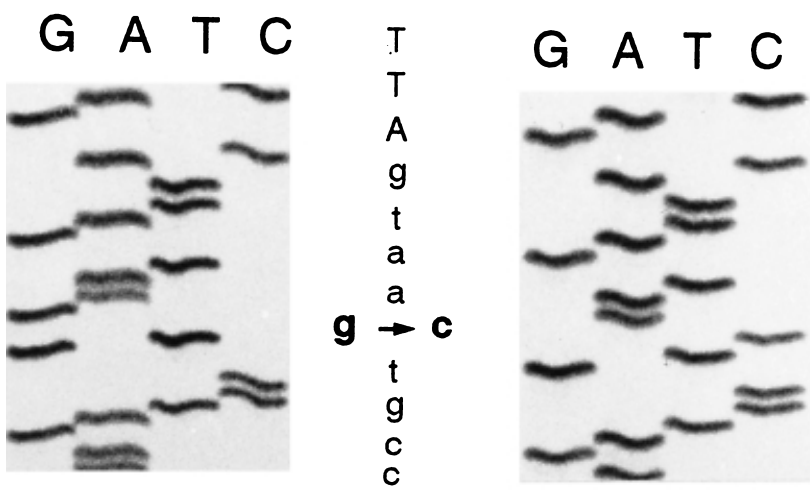

M

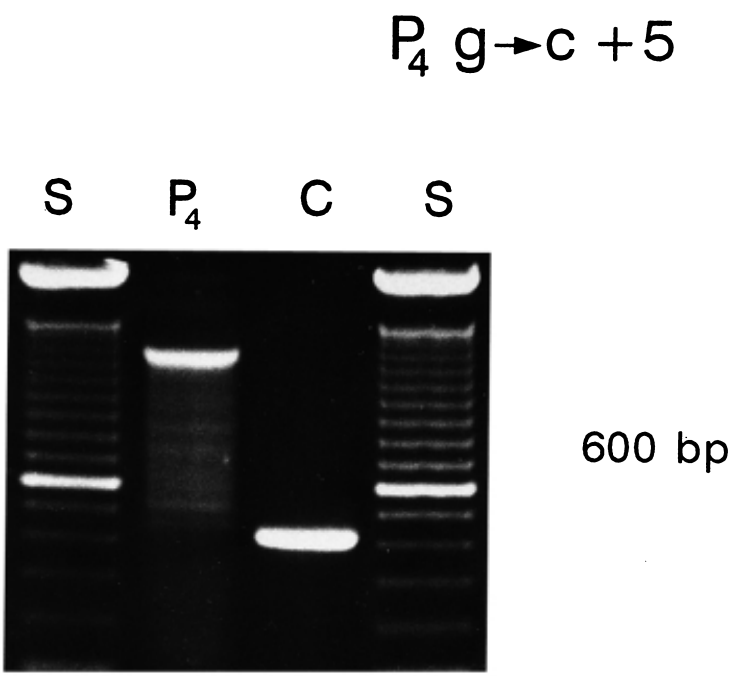

Fig. 2. Sequencing comparison of the exon $6 /$ intron 6 boundaries of the mutant and normal $A R$ gene. Patient 4 presents a single-base substitution $(\mathrm{g} \rightarrow \mathrm{c})$ at position +5 of the splice donor site, which is not present in the DNA of the patient's mother $(M)$ (upper panel). The lower panel shows the size comparison of the AR cDNA (exons 6-8) amplified by reverse transcriptase-polymerase chain reaction. Control cDNA yielded an expected fragment of $432 \mathrm{bp}$, whereas that of patient 4 $\left(p_{4}\right)$ yielded a band of $1223 \mathrm{bp}$ that spans from exon 6 through exon 8 , including the entire intron 6. Outer lanes are 100-bp DNA markers $(S)$

mon sites of amino acid substitution in the $A R$ gene. As analyzed in mutant fibroblasts, the Pro682 $\rightarrow$ Thr substitution renders the AR with limited binding activity. The second disorder detected was a $\mathrm{C} \rightarrow \mathrm{G}$ change at nucleotide 2493 in exon 4. Apparently, the nonconservative replacement of glutamine with glutamic acid at amino acid 711, which is also a conserved residue, does not affect the AR binding activity. As in these cases, it has been estimated that about $75 \%$ of the mutations in the SBD have occurred at residues identical in at least two other members (i.e., PR, GR) of the steroid receptor subfamily (Quigley et al. 1995). Both mutations P682T and Q711E lie on the hinge region, an area known to be important for dimerization and nuclear translocation of the AR (Simental et al. 1991; Wong et al. 1993; Zhou et al. 1994a).
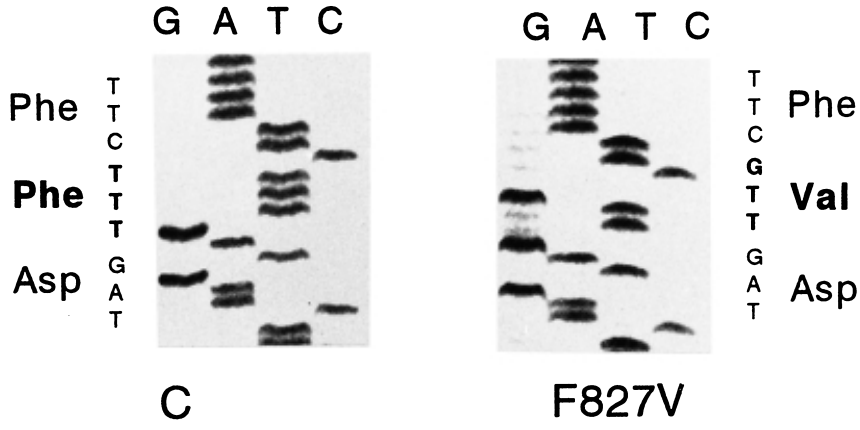

\section{Exon 8}

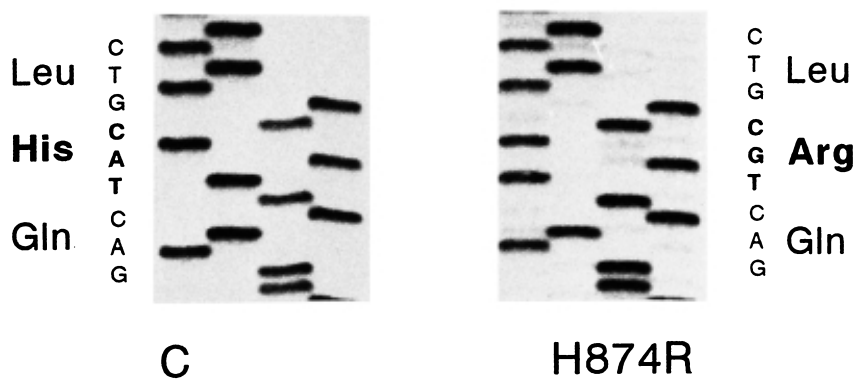

Fig. 3. Partial sequence of exons 7 and 8 of the $A R$ gene showing a $\mathrm{T} \rightarrow \mathrm{G}$ transversion in patient 5 causing Phe827-Val and an $\mathrm{A} \rightarrow \mathrm{G}$ transition in patient 6 causing His874-Arg. Control DNA samples $(C)$ were obtained from unrelated normal males

\section{Exon 8}

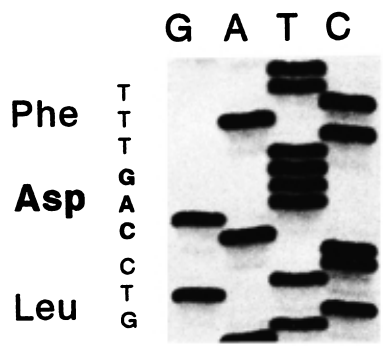

C

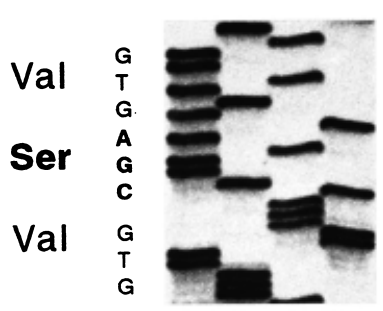

C

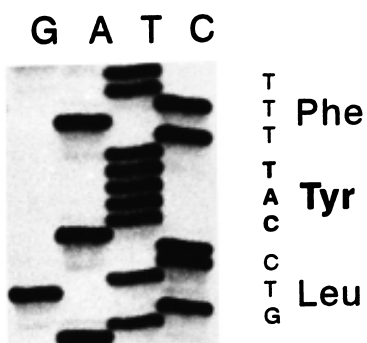

D879Y

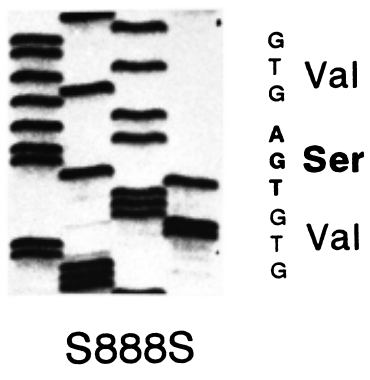

Fig. 4. Partial sequence of exon 8 of the $A R$ gene showing a $\mathrm{G} \rightarrow \mathrm{T}$ tranversion in subject 7 that changes the sense of codon 879 from aspartic acid to tyrosine. Patient 8 had a $\mathrm{C} \rightarrow \mathrm{T}$ replacement leading to Ser888-Ser. Control DNA samples $(C)$ were obtained from unrelated normal males 
Patient 3, with a completely female phenotype, presented a Gly $743 \rightarrow$ Glu mutation in exon 5. Interestingly, a different molecular lesion affecting this codon has been reported in prostatic cancer (Gottlieb et al. 1999). The mutated receptor of our patient showed a positive binding activity in cytosolic preparations; however, no specific binding at the nuclear level could be detected, which suggests that this particular substitution might be altering AR nuclear transport. In this regard, molecular studies using AR mutants, constructed by PCR mutagenesis, have shown that the 48 amino acids of exon 5 in the SBD play a major role not only in binding specificity, but also in inhibiting target signal activity in the abscence of androgen binding (Zhou et al. 1994b). It is noteworty that patient 3 as well as patient 6, both with CAIS, presented remnants of Müllerian derivatives (Ulloa-Aguirre et al. 1986, 1990).

Sequence analysis in patient 4 showed a single mutation in position +5 of the $5^{\prime}$ splicing region. The $\mathrm{g} \rightarrow \mathrm{c}$ nucleotide replacement abolishes normal splicing at the exon 6/intron 6 boundary and is associated with a CAIS phenotype with total absence of androgen binding. This change was not found in the maternal DNA, which is consistent with a de novo mutation. By studying AIS families with only one affected member, Hiort et al. (1998) found a high rate of de novo mutations (about 27\%) in the $A R$ gene. Likewise, in a recent study, a different $\mathrm{g} \rightarrow \mathrm{t}$ transversion in the splice donor site of intron 6 was detected in a French child with AIS (Sammarco et al. 2000). Unlike the receptor in our patient, the mutated receptor from this patient exhibited reduced binding capacity $\left(B_{\max }\right)$, thus indicating that the replacement of guanine with cytosine at this position $(+5)$ is deleterious for receptor functioning. Most splice-junction mutations identified to date are associated with a CAIS phenotype (Gottlieb et al. 1999).

In patient 5, who presented complete AIS, we found a hitherto unreported $T \rightarrow G$ transversion in exon 7 . The conservative replacement of phenylalanine with valine at amino acid 827, which is a well-conserved site, seems to cause an important alteration, as it lies within a segment considered critical for AR activity (Zhou et al. 1994a,b; Thornton and Kelley 1998).

The sixth mutation was detected in an individual with CAIS (Quigley's grade 7), having an $A \rightarrow G$ transition at nucleotide 2980 in exon 8; this change has never been detected in AIS. Nevertheless, the mutation is located in the same codon as a mutation previously reported in prostatic cancer, although with a different amino acid substitution. Functional studies show that this change (at nucleotide 2981) alters the hormone specificity in such a way that mutant receptors could also be activated by estrogens, progesterone, and hydroxyflutamide (Taplin et al. 1995; Tan et al. 1996). That the mutation H874R impairs ligand specificity appears unlikely since it is associated with a total lack of binding activity (Table 1 ).

Finally, two mutations in exon 8 that do not affect AR binding were observed in subjects with PAIS. Both mutations lie within or nearby the activation function-2 (AF-2) core domain, a region involved in the interaction with the coactivator TIF2 (Slagsvold et al. 2000). A G $\rightarrow$ T replacement in the first nucleotide (2997) of codon 879 was detected in two siblings who were raised as males and exhibited a similar phenotype. As observed in patient 7, most males with gynecomastia resulting from PAIS have molecular lesions in the SBD (Giwercman et al. 2000). Likewise, adjacent residues (i.e., 877 and 880 ) are predicted to be in contact with the ligand (Thornton and Kelley 1998).

The last mutation identified was a $\mathrm{C} \rightarrow \mathrm{T}$ transition at nucleotide 3026, found in a 3-year-old child who presented with perineal hypospadias as the main stigma. Although this silent mutation affected a highly conserved residue (Ser888), there was no amino acid replacement. However, it is well recognized that changes in synonym codons might influence transcription, processing, or translation (Beaudet et al. 1995). Patient 8 had the AGC $\rightarrow$ AGT mutation in exon 8. Such a change has not been described previously; therefore we cannot exclude the possibility of a polymorphism. However, molecular screening of exon 8 performed on more than 130 chromosomes of karyotypic males suggests strongly that the change found at codon 888 represents a mutation with phenotypic expression and not a genetic polymorphism. In support of this view, molecular evidence indicates that mutagenesis of residue 888 does not influence androgen binding or LBD homodimerization, but decreases the interaction with the coactivator TIF2 and with the $\mathrm{NH}_{2}-$ terminal domain (Berrevoets et al. 1998). Furthermore, recent molecular studies suggest the existence of a functional element centered around this residue (Met886), which could have a role, not in ligand binding, but in interdomain and coactivator interactions (Ghadessy et al. 1999). More than 12 different silent mutations in the AR have been reported that result in partial or complete AIS and even in prostatic cancer; the mutations R210R, E211E, $\mathrm{V} 511 \mathrm{~V}$, and $\mathrm{L} 838 \mathrm{~L}$ are among the AR alterations that may impair the normal phenotypic development in males (Gottlieb et al. 1999).

In summary, we identified eight new missense mutations in the $A R$ gene of Mexican patients clinically diagnosed with AIS. Our data support the view that these disorders result in a nonfunctional or subfunctional protein, causing masculinization defects of varying degrees. The results also underline the importence of the existence of an entire SBD for proper AR functional activity.

Acknowledgments This work was supported by CONACYT (México), Grant 0010P-M.

\section{References}

Ahmed SF, Cheng A, Dovey L, Hawkins JR, Martin H, Rowland J, Shimura N, Tait AD, Hughes IA (2000) Phenotypic features, androgen receptor binding, and mutational analysis in 278 clinical cases reported as androgen insensitivity syndrome. J Clin Endocrinol Metab 85:658-665

Beaudet AL, Scriver CR, Sly WS, Valle D (1995) Genetics, biochemistry and molecular basis of variant human phenotypes. In: Scriver CR, Beaudet AL, Sly WS, Valle D (eds) The metabolic and molecular bases of inherited disease. McGraw-Hill, New York, pp 53-118 
Berrevoets CA, Doesburg P, Steketee K, Trapman J, Brinkmann AO (1988) Functional interactions of the AF-2 activation domain core region of the human androgen receptor with the amino-terminal domain and with transcriptional coactivator TIF2 (transcriptional intermediary factor 2). Mol Endocrinol 12:1172-1183

Chang C, Kokontis J, Liao S (1988) Molecular cloning of human and rat complementary DNA encoding androgen receptors. Science 240:324-326

DeBellis A, Quigley CA, Cariello NF, El-Awady MK, Sar M, Lane ML, Wilson EM, French FS (1992) Single base mutations in the human androgen receptor gene causing complete androgen insensitivity: rapid detection by a modified denaturing gradient gel electrophoresis technique. Mol Endocrinol 6:1909-1920

French FS, Lubahn DB, Brown TR, Simental AJ, Quigley CA, Yarbrough WG, Tan J, Sar M, Joseph DR, Evans BAJ, Hughes IA, Migeon CJ, Wilson EM (1990) Molecular basis of androgen insensitivity. Recent Prog Horm Res 46:1-42

Ghadessy FJ, Lim J, Abdullah AAR, Paner-Raymond V, Choo CK, Lumbroso R, Tut TG, Gottlieb B, Pinsky L, Trifiro MA, Yong L (1999) Oligospermic infertility associated with an androgen receptor mutation that disrupts interdomain and coactivator (TIF2) interactions. J Clin Invest 103:1517-1525

Giwercman A, Kledal T, Schwartz M, Giwercman YL, Leffers H, Zazzi H, Wedell A, Skakkebaek NE (2000) Preserved male fertility despite decreased androgen sensitivity caused by a mutation in the ligand-binding domain of the androgen receptor gene. J Clin Endocrinol Metab 85:2253-2259

Gottlieb B, Beitel LK, Lumbroso R, Pinsky L, Trifiro M (1999) Update of the androgen receptor gene mutations database. Hum Mutat 14:103-114

Hiort O, Sinneker GHS, Holterhus P-M, Nitsche EM, Kruse K (1998) Inherited and de novo androgen receptor gene mutations: investigation of single-case families. J Pediat 131:939-943

John SWM, Weilzner G, Rozen R, Scriver CR (1991) A rapid procedure for extracting genomic DNA from leukocytes. Nucleic Acids Res 19:408

López-Otín C, Diamandis EP (1998) Breast and prostate cancer: an analysis of common epidemiological, genetic, and biochemical features. Endocr Rev 19:365-396

Lubahn DB, Joseph DR, Sullivan PM, Willard HF, French FS, Wilson EM (1988) Cloning of human androgen receptor complementary DNA and localization to the X chromosome. Science 240:327-330

Lubahn DB, Brown TR, Simental JA, Higgs HN, Migeon CJ, Wilson EM, French FS (1989) Sequence of the intron/exon junctions of the coding region of the human androgen receptor gene and identification of a point mutation in a family with complete androgen insensitivity. Proc Natl Acad Sci USA 86:9534-9538

McPhaul MJ, Marcelli M, Zoppi S, Griffin JE, Wilson JD (1993) Genetic basis of endocrine disease: 4 . The spectrum of mutations in the androgen receptor gene that causes androgen resistance. J Clin Endocrinol Metab 76:17-23

Medina M, Chávez B, Pérez-Palacios G (1981) Defective androgen action at the cellular level in the androgen resistance syndromes: I. Differences between the complete and incomplete testicular feminization syndromes. J Clin Endocrinol Metab 53:1243-1246

Orita M, Suzuki Y, Hayashi K (1989) Rapid and sensitive detection of point mutations and DNA polymorphisms using the polymerase chain reaction. Genomics 5:874-879

Quigley C, DeBellis A, Marschke KB, El-Awady MK, Wilson EM, French FS (1995) Androgen receptor defects: historical, clinical, and molecular perspectives. Endocr Rev 16:271-321

Sammarco I, Grimaldi P, Rossi P, Cappa M, Moretti C, Frajese G, Geremia R (2000) Novel point mutation in the splice donor site of exon-intron junction 6 of the androgen receptor gene in a patient with partial androgen insensitivity syndrome. J Clin Endocrinol Metab 85:3256-3261

Sawai H, Komori S, Sakata K, Nakae K, Shima H, Matsumoto F, Matsumoto H, Onishi Y, Okada Y, Yoshida O, Koyama K (2000) Molecular analysis of familial androgen insensitivity syndrome due to replacement of glutamic acid 802 by lysine. J Hum Genet 45:342345

Simental JA, Sar M, Lane ML, French FS, Wilson EM (1991) Transcriptional activation and nuclear targeting signals of the human androgen receptor. J Biol Chem 66:510-518

Slagsvold T, Kraus I, Bentzen T, Palvimo J, Saatcioglu F (2000) Mutational analysis of the androgen receptor AF-2 (activation function 2) core domain reveals functional and mechanistic differences of conserved residues compared with other nuclear receptors. Mol Endocrinol 14:1603-1617

Tan J-A, Sharief Y, Hamil KG, Gregory CW, Zang D-Y, Sar M, Mohler JL, French FS (1996) Altered ligand specificity of a mutant androgen receptor (AR) in the androgen dependent human prostate cancer xenograft, CWR-22: comparision with the LNCaP mutant AR. Proc Am Urol Assoc 155 Suppl 340A (120)

Taplin M-E, Bubley GJ, Shuster TD, Frantz ME, Spooner AE, Ogata GK, Keer HN, Balk P (1995) Mutation of the androgen-receptor gene in metastatic androgen-independent prostate cancer. N Engl J Med 332:1393-1398

Thornton JW, Kelley DB (1998) Evolution of the androgen receptor: structure-function implications. Bioessays 20:860-869

Ulloa-Aguirre A, Méndez JP, Angeles A, Fernández del Castillo C, Chávez B, Pérez Palacios G (1986) The presence of Müllerian remnants in the complete androgen insensitivity syndrome: a steroid hormone-mediated defect? Fertil Steril 45:302-305

Ulloa-Aguirre A, Chávez B, Méndez JP, Saavedra D, Pérez-Palacios G (1988) Inherited impairment of nuclear uptake as a cause of familial androgen insensitivity. Eur J Obstet Gynecol Reprod Biol 28:317329

Ulloa-Aguirre A, Méndez JP, Chávez B, Carranza-Lira S, Angeles A, Pérez Palacios G (1990) Incomplete regression of Müllerian ducts in the androgen insensitivity syndrome. Fertil Steril 53:1024-1028

Vilchis F, Méndez JP, Canto P, Lieberman E, Chávez B (2000) Identification of missense mutations in the SRD5A2 gene from patients with steroid 5 $\alpha$-reductase 2 deficiency. Clin Endocrinol 52:383-387

Wong C-I, Zhou Z-X, Sar M, Wilson EM (1993) Steroid requirement for androgen receptor dimerization and DNA binding. J Biol Chem 268:19004-19012

Zhou Z-X, Wong C-I, Sar M, Wilson EW (1994a) The androgen receptor: an overview. Recent Prog Horm Res 49:249-274

Zhou Z-X, Sar M, Simental JA, Lane MV, Wilson EM (1994b) A ligand-dependent bipartite nuclear targeting signal in the human androgen receptor. J Biol Chem 269:13115-13123 